\title{
Outpatient, Multidisciplinary Treatment of Morbidly Obese Patients: A Two-Year Retrospective Study
}

\author{
Randi Vangen Skyrud ${ }^{1}$, Jan Aaseth ${ }^{1}$ and Grethe Støa Birketvedt ${ }^{*}, 2$ \\ ${ }^{I}$ Department of Medicine, Innlandet Hospital Trust, Norway; ${ }^{2}$ Oslo University Hospital, Aker, Department of Bariatric \\ Surgery and Morbid Obesity, Norway
}

\begin{abstract}
Introduction: Morbid obesity is a significant risk factor for type 2 diabetes, dyslipidemia and cardiovascular disease. A weight reduction of $5-10 \%$ is considered a great health benefit. However, no sufficient documentation exists today on the long-term effects of outpatient treatment of obesity. This study aims to improve health parameters in morbidly obese patients in a 2 year treatment study under medical supervision in group environment. Materials and Methodology: In a multidisciplinary outpatient treatment program, 141 patients were in writing informed about the program, and 69 morbidly obese patients ((BMI $>40 \mathrm{~kg} / \mathrm{m}^{2}$ or BMI $>35 \mathrm{~kg} / \mathrm{m}^{2}$ with comorbidities) (18-65 years)) agreed to participate and were non-randomly enrolled in a retrospective cohort study at Innlandet Hospital Trust (Kongsvinger division) in May 2010. The patients were observed retrospectively for a 2-year period from 2007 till 2009. The intervention program in the cohort consisted of group therapy and individual interviews with guidance on physical activity, diet, lifestyle changes and behavioral adjustments. Body weight, waist circumference and comorbidities were assessed regularly. Results: The treatment resulted in a $10 \%$ weight loss in average. Blood pressure and blood lipids improved. Approximately $10 \%$ of the patients obtained a weight reduction equal to patients having undergone bariatric surgery. The drop-out rate was $10 \%$. Conclusions: This study concludes that our treatment program contributes significantly to weight loss and improves metabolic risk factors.
\end{abstract}

Keywords: Morbid obesity, weight loss, multidisciplinary treatment, lifestyle modifications.

\section{INTRODUCTION}

The prevalence of obesity (body mass index, BMI $\geq 30$ $\mathrm{kg} / \mathrm{m}^{2}$ ) has dramatically increased globally during the last few decades $[1,2]$. According to the World Health Organization fact sheet No. 311. 2006, recent data point to more than 1.6 billion overweight adults (body mass index (BMI)> $25 \mathrm{~kg} / \mathrm{m}^{2}$ ) and at least 400 million clinically obese (BMI> $30 \mathrm{~kg} / \mathrm{m}^{2}$ ) worldwide. The individual and public health consequences of overweight and obesity are serious as both conditions are independent risk factors for type 2 diabetes, cardiovascular disease and hypertension. Morbid obesity, defined as a BMI $>40 \mathrm{mg} / \mathrm{m}^{2}$ or a BMI $>35 \mathrm{mg} / \mathrm{m}^{2}$ with comorbidities, is associated with a higher cluster of diseases and therefore represents a major risk factor for cardiovascular morbidity and mortality [3]. In this cluster, known as the metabolic syndrome [4], morbid obesity is a major factor known to precede the other risk factors. Treatment and prevention of obesity are today a health policy priority throughout the world. Morbidly obese patients can be treated successfully with bariatric surgery $[5,6]$, but this approach can only be offered a small percentage of the morbidly obese patients. Comprehensive lifestyle intervention programs have demonstrated, to some extent, a significant short-term weight reduction [7-9]. However, the effectiveness of longterm (more than 2 years) outpatient treatment of morbid

*Address correspondence to this author at the Oslo University Hospital, Aker, Department of Bariatric Surgery and Morbid Obesity, Norway; Tel: +47 23033097; E-mail: gsb42nor@aol.com obesity is still poorly documented [7,8], and consequently further development and evaluation of intervention programs are needed. Any evaluation should take into account that small, but maintained weight loss can have significant health benefits [10].

Conservative treatment consisting of diet, exercise and behavioral adjustments is the cornerstone in any obesity treatment. Research has shown that a conservative treatment only result in a short term weight loss that is not maintained over time [11]. The aim of the present study was to develop and implement a treatment program for morbidly obese patients, using a cognitive strategy for giving the obese patients a deeper insight in the relationship between their life-style and their weight. The primary purpose of this article is to demonstrate the outpatient treatment principles that resulted in a sustained weight loss in morbidly obese patients through a two-year-period of treatment.

\section{MATERIALS AND METHODOLOGY}

The study was conducted in an outpatient clinic of the Innlandet Hospital Trust, Kongsvinger. The intervention program was developed as a treatment for morbidly obese subjects (18-65 years) (BMI $\geq 40 \mathrm{~kg} / \mathrm{m}^{2}$, or BMI $\geq 35 \mathrm{~kg} / \mathrm{m}^{2}$ with at least one obesity-related comorbidity)) [5]. The study was non-randomized and had no control group. The study participants were admitted by their physician in the primary health care. During the initial three months, the admitted subjects, from close to equal socioeconomical community (n $=156$ ) underwent in $2007 \mathrm{a}$ baseline medical screening at the 
hospital outpatient clinic. Patients qualifying for bariatric surgery were excluded [12].

The baseline clinical consultation was carried out by a specialist in internal medicine and endocrinology, and included a complete medical examination and laboratory analyses. Follow-up examinations by a physician were carried out twice yearly.

After the two-year-period of life-style intervention, 15 patients $(9.6 \%)$ of the included subjects had dropped out of the intervention program. The remaining 141 patients were in May 2010 asked by the investigator in a written letter sent by mail to participate in the retrospective study. Written informed consent was provided by 69 subjects, 41 women and 28 men (Table 1).

Table 1. Characteristics at Baseline for the Studied Patients Compared to the whole Group. Data are Given as Mean and Standard Deviation (S.D.) or \%

\begin{tabular}{|c|c|c|}
\hline & $\begin{array}{c}\text { Studied patients } \\
(\mathbf{n = 6 9 )}\end{array}$ & $\begin{array}{c}\text { Whole group } \\
(\mathbf{n = 1 4 1 )}\end{array}$ \\
\hline \hline Age, years (SD) & $49,7(11)$ & $44,9(22)$ \\
\hline Weight, $\mathrm{kg}(\mathrm{SD})$ & $122(22)$ & $128(20)$ \\
\hline Gender (\%female) & $59 \%$ & $64 \%$ \\
\hline Type 2 diabetes & $30 \%$ & $38 \%$ \\
\hline Hypertension & $53 \%$ & $55 \%$ \\
\hline
\end{tabular}

The study was approved by the Regional Ethical Committee, formerly known as the Eastern Region of Norwegian Health Authority. The study was conducted according to the guidelines laid down in the Declaration of Helsinki.

The study is registered in the ClinicalTrial.gov-registry under trial number NCT 01249209.

\section{Intervention}

The entire intervention program was organized and carried out at the hospital outpatient clinic. After the baseline medical screening, the subjects were scheduled for regular meetings in therapeutic groups of about eight participants in each group. The intervention program was developed during a five-year-period prior to the present study, through collaboration by specialized endocrinologists, psychologists, physiotherapists and nurses.

Using a cognitive approach [12-15] the group leaders, usually trained nurses, defined the study objective as a weight loss of at least $10 \%$ in each patient. At the initial group meeting, the participants expressed their future aspiration for weight loss. The following group sessions emphasized motivation and changes in lifestyle. Furthermore, the sessions focused on emotional aspects of a sedentary behavior, as well as on topics related to nutrition, physical activity and co-morbidities as a consequence of obesity. The participants were encouraged to use a food diary from the start of the treatment period.

The sessions took place weekly the first 6 months. From 6 to 12 months the participants met for monthly sessions,
The $2^{\text {nd }}$ year the patients met 10 times. Totally, there were 40 group meetings during the two-year-period. During the course of the various meetings, the group itself soon assumed the role of a therapeutic resource.

The group leaders aimed to facilitate the group dynamics where participants shared attitudes and experiences, supported each other, and found working solutions together.

The participants signed a contract at the outset of the study. This contract contained internal confidentiality agreement in the group, and rules for attendance and absence.

No special diet or weight-loss drugs were prescribed, but the patients were encouraged to follow the guidelines of the Norwegian National Council of Nutrition [16].

A main focus in the treatment was to motivate to increased physical training and activity. In this part of the approach, the group collaborated with a physiotherapist. During the first months when the exercise took place in a swimming pool, the participants were guided by a physiotherapist. Moreover, a main goal was to help participants choose activities that they enjoyed and that could be implemented in their everyday life. The patients were motivated to engage in both strength training and endurance training. They were encouraged to use an exercise diary as well as a pedometer as aids in exercising and training.

Individual consultations by a hospital internist took place bi-annually, and by a trained nurse or a psychologist when needed. Changes in medications were made on an individual basis, either by the patient's general practitioner or by a hospital physician.

During the successive group meetings, as the participants gradually attained increased insight into the relationship between lifestyle and weight, the responsibility for their lifestyle changes were transferred from the coach to themselves.

Toward the end of the intervention, they were expected to take more part in improving their own health and therefore were made responsible for their own priorities in relation to choices of activities, food and drinks.

The two-year intervention period was terminated by a complete medical examination and an evaluation and summary of results, experiences and further motivation.

\section{Outcome Variables and Data Collection}

Blood pressure, weight and waist circumference were examined. Blood samples were drawn at start of the study and repeated after $6,12,18$ and 24 months.

Patient data were stored in the hospital computer system and were obtained from medical documentation and laboratory tests. Blood samples were analyzed by standard methods at Innlandet Hospital. In two cases laboratory test results were obtained from the patients' general practitioner. The weighing of each patient was carried out just before the group session or before the individual counseling hours. The scale used throughout the study was approved for use in hospitals, and had internal controls, and calibration. Waist measurement was standardized, and was measured at the midpoint between the lateral lower ribs and iliac crest. 


\section{Statistics}

Normally distributed continuous data were presented by mean values with standard deviation (SD). Non-normally distributed data were presented by the median value. Paired $\mathrm{t}$-test and non-parametric analysis (Wilcoxon signed-rank test) were used in comparisons of normally distributed and non-normally distributed continuous paired data, respectively. A two-sided $p$-value $<0.05$ was considered statistically significant. Calculations were carried out using the SPSS version 15.0 for Windows (SPSS Inc., Chicago, Illinois, USA).

\section{RESULTS}

Average weight and BMI at the start of the intervention period were $122 \mathrm{~kg}$ and $41.6 \mathrm{~kg} / \mathrm{m}^{2}$, respectively (Table 2). The total reduction in weight and BMI was $10.5 \%$ after two years. The results after $6,12,18$ and 24 months of the intervention, showed an increasing weight loss over the whole period (Fig. 1), but the fastest rate of weight reduction was observed during the initial 6-month-period. Average weight loss was $10.8 \mathrm{~kg}$ for women and $17.3 \mathrm{~kg}$ for men during the treatment period. The reduction in waist circumference was in average 7\%. Significant reductions in systolic and diastolic blood pressure, cholesterol and triglycerides were also observed (Table 2). The criteria for metabolic syndrome were met by $93 \%$ before intervention and $76 \%$ after the two-year lifestyle intervention. Approximately $10 \%$ of the group had an almost equal weight reduction, about $30 \%$, as that achieved by obesity surgery [21, 22]. No reported adverse events in our group were ascribed to the lifestyle intervention.

Before treatment, $20 \%$ of the subjects used lipid-lowering drugs. The corresponding figures for antihypertensive therapy, as well as for anti-diabetic medication, were $30 \%$. Their treatment regimens were not terminated, although in a few cases they were adjusted, during the intervention period. The final evaluation of the food diaries of the participants indicated that at least $80 \%$ had succeeded in establishing a regular pattern of meal intakes.

Table 2. Patient Characteristics $(n=69)$ Listed as Mean and Standard Deviation (SD) before and after 2 Years of Lifestyle Treatment

\begin{tabular}{|c|c|c|c|}
\hline & At Baseline & After 2 Years & P-Value \\
\hline \hline Weight $(\mathrm{kg})$ & $122(22)$ & $109(20)$ & 0.000 \\
\hline BMI $\left(\mathrm{kg} / \mathrm{m}^{2}\right)$ & $41.6(5.9)$ & $37.5(5.5)$ & 0,000 \\
\hline Waist circumference $(\mathrm{cm})$ & $125(14)$ & $114(15)$ & 0.000 \\
\hline HbA1c $(\%)$ & $6.1(1.1)$ & $6.0(1.0)$ & 0.059 \\
\hline Fasting glucose $(\mathrm{mmol} / \mathrm{l})$ & $6,5(1.9)$ & $6,3(2.0)$ & 0.378 \\
\hline Uric acid $(\mathrm{mmol} / \mathrm{l})$ & $370(95)$ & $355(92)$ & 0.121 \\
\hline Cholesterol $(\mathrm{mmol} / \mathrm{l})$ & $5.3(0.9)$ & $5.0(1.0)$ & 0.002 \\
\hline LDL (mmol/1) & $3.4(0.6)$ & $3.2(0.9)$ & 0.024 \\
\hline HDL (mmol/l) & $1,28(0,3)$ & $1,26(0,3)$ & 0,494 \\
\hline Triglycerides $(\mathrm{mmol} / \mathrm{l})$ & $1.5(0.6)$ & $1.3(0.6)$ & 0.003 \\
\hline Systolic BP. $(\mathrm{mm} \mathrm{Hg})$ & $140(21)$ & $132(16)$ & 0.003 \\
\hline Diastolic BP. $(\mathrm{mm} \mathrm{Hg})$ & $87(11)$ & $81(9)$ & 0.000 \\
\hline
\end{tabular}

\section{DISCUSSION}

In this study, the intensive lifestyle intervention resulted in a mean weight loss of about $10 \%$ in morbidly obese subjects who completed the 2-year program. A similar weight loss was obtained in the cohort of 141 subjects, according to our quality assurance program. This is identical with the weight loss recently reported among a group completing intensively treatment in the Louisiana obese subjects

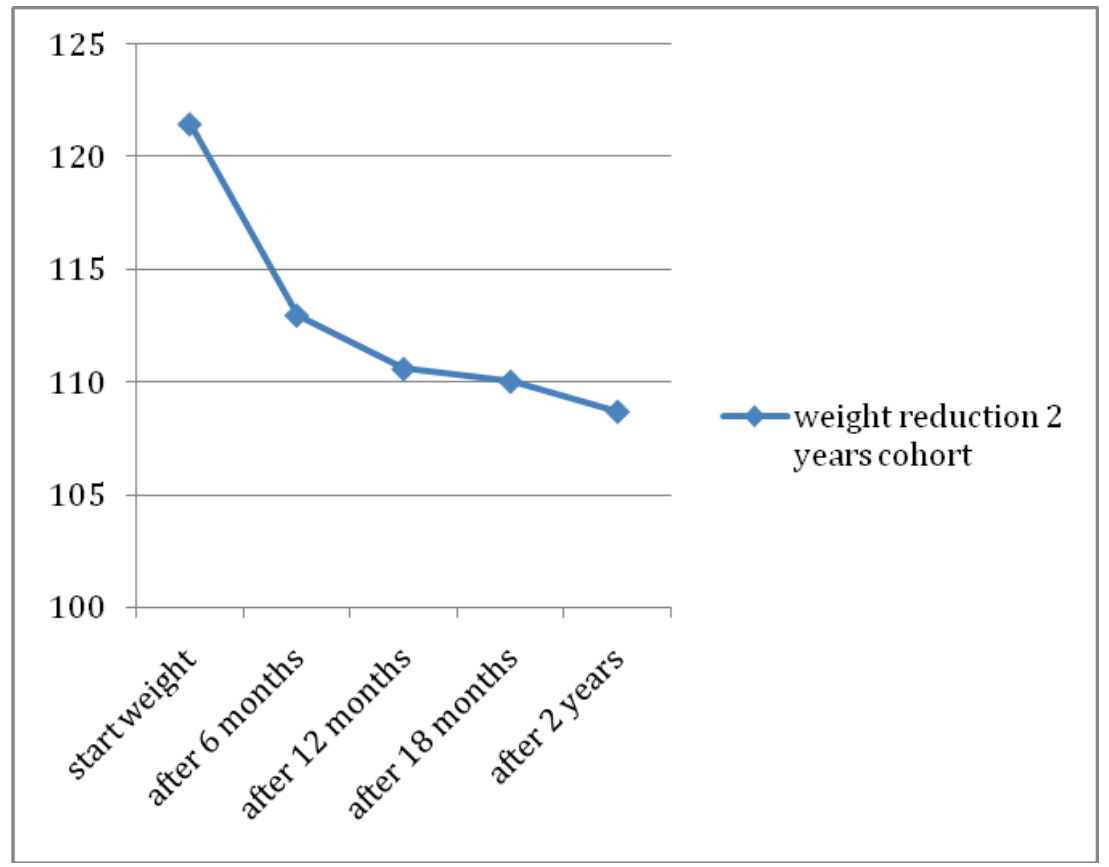

Fig. (1). Mean values for weight reduction during the two-year-period of treatment in the studied group $(n=69)$. 
study [8]. However, their study in the primary health care had a $51 \%$ completion rate, whereas $90 \%$ completed the present study on patients referred to the secondary health care.

Compared with other recent studies, the treatment regimen used in our program resulted in significant health benefits. In a Finnish intervention study of obese people at high risk for diabetes, the four-year incidence of type- 2 diabetes decreased by nearly $60 \%$ although the average weight loss was less than 5\% [17]. In another prospective Nordic study, obese subjects were treated with a low-energy diet during an initial 8-week-period, before randomization either to lifestyle intervention or to the same lifestyle intervention including a weight-reducing drug. After three years, the drug treated group achieved an average weight loss of $8 \%$ and the group with lifestyle intervention lost $6 \%$ of their weight [18].

A retrospective study of patients who had completed intensive intervention at the Ebeltoft clinic in Denmark showed a sustained weight loss of about $5 \%$ two years after starting the intervention program [19].

The weight loss of about $7 \%$ observed in our study after a 6-month-period of weekly sessions is comparable to the results recently reported by Swetkey et al. [20]. However, in contrast to their participants, our attendants continued to lose weight during the subsequent months. Thus, after one year our intensive approach led to a mean weight loss of about $9 \%$, which is comparable to the results recently reported by Hofsø et al. [9] and Martins et al. [21], the latter study reporting means ranging from $5 \%$ to $15 \%$ by using different conservative regimens for one year. Moreover, the weight loss in our study was even better than weight loss of $5 \%$ reported by Martins et al. [22] in a hospital outpatient program.

The health benefits of $10 \%$ weight reduction and weight loss maintenance have both psychosocial and metabolic aspects. We are aware of the limitations of the study do to lack of controls and the non-randomization. But we believe that our findings are important in determining the effectiveness of repetitive cognitive and life style interventions in weight loss management, and the effectiveness of maintained weight loss over a long period of time.

The metabolic health gain is illustrated by the substantially decreased number of patients with metabolic syndrome, observed in our cohort. The relatively positive results obtained in our study may be related to the recruitment of patients from the primary to the secondary health care. Thus, the selection of patients implies that the subjects experience a motivation for treating their own disease. The relatively high percentage completing the program may be associated with the selection or the intervention process. However, $10 \%$ of the participants left the intervention program before its termination. In addition, almost $20 \%$ could have been classified as non-responders with a weight reduction of less than $5 \%$.

The implementation of the program into the primary health care is a challenge needed to be met in the future. Our initial goal was to identify factors that facilitate or prevent the patients' motivation for changing their lifestyle over time. The future challenge will be to motivate morbidly obese patients to stay focused in changing their lifestyle by making behavioral adjustments. Further long-term studies in lifestyle intervention are needed in order to fully understand why weight maintenance and changes over time are so difficult. Therefore, future focus should be to study the biochemistry of the human body when weight changes take place and after a longer weight maintenance period. However, this was beyond the aim of this study.

\section{ACKNOWLEDGEMENT}

Funds provided from Innlandet Hospital Trust are gratefully acknowledged.

\section{REFERENCES}

[1] Sturm R. Increases in morbid obesity in the USA: 2000-2005. Public Health 2007; 121: 492-6.

[2] Holmen J, Midthjell K, Krokstad S, Lingaas Holmen T. Obesity and type 2 diabetes in Norway: New data from the HUNT Study. Obes Facts 2009; 2: 256.

[3] Katzmarzyk PT, Church TS, Janssen I, Ross R, Blair SN. Metabolic syndrome, obesity, and mortality: impact of cardiorespiratory fitness. Diabetes Care 2005; 28: 391-7.

[4] Grundy SM, Cleeman JI, Daniels SR, et al. Diagnosis and management of the metabolic syndrome: an American Heart Association / National Heart, Lung, and Blood Institute Scientific Statement. Circulation 2005; 112: 2735-52.

[5] Buchwald H, Oien DM. Metabolic/bariatric surgery worldwide 2008. Obesity Surgery 2009; 19: 1605-11

[6] Sjöström L, Lindroos AK, Peltonen M, et al. (Swedish Obese Subjects Study Scientific Group). Lifestyle, diabetes, and cardiovascular risk factors 10 years after bariatric surgery. $\mathrm{N}$ Engl J Med 2004; 351: 2683-93.

[7] Look AHEAD Research Group (Pi-Sunyer X, Blackburn G, Brancati FL, et $a$ l). Reduction in weight and cardiovascular disease risk factors in individuals with type 2 diabetes: one-year results of the Look AHEAD trial. Diabetes Care 2007: 30; 1374-83.

[8] Ryan DH, Johnson WD, Myers VH, et al. Nonsurgical weight loss for extreme obesity in primary care settings: results of the Louisiana Obese Subjects Study. Arch Internal Med 2010: 170; 146-54.

[9] Hofsø D, Nordstrand N, Johnson IK, et al. Obesity-related cardiovascular risk factors after weight loss: a clinical trial comparing gastric bypass surgery and intensive lifestyle intervention. Eur J Endocrinol 2010: 163: 735-45.

[10] Blackburn G. Effect of degree of weight loss on health benefits. Obes Res 1995; 3 (Suppl 2): 211s-6.

[11] Wadden TA, Butryn ML Wilson C. Lifestyle modofocation for the menagement of obesity. Gastroenterology 2007; 132: 2226-38.

[12] Norwegian Directorate of Health. Obesity treatment and prevention in Norway. January $10^{\text {th }}, 2010$ ).

[13] Melin I. Handbook for practical clinical treatment of obesity, and metabolic syndrome on cognitive and conventional treatment. Holmberg, Malmö 2007.

[14] Brownell, K. The LEARN program for weight management. Lifestyle, exercise, attitudes, relationship, nutrition. Am Publ Health Co 2004.

[15] Vifladt EH, Hopen L Health Education. Interaction of learning and mastery. Oslo: National Centre for learning and coping with chronic illness, 2004.

[16] Buhl C. Overweight and dieting. Psychological understanding and treatment of obesity. Oslo: Universitetsforlaget 1996.

[17] Ministry of Health and Care Services. Recipe for a healthier diet. Norwegian Action Plan on Nutrition (2007-2011).

[18] Tuomilehto J, Lindström J, Eriksson JG, et al. Prevention of type 2 diabetes by changes in lifestyle among subjects with impaired glucose tolerance. N Engl J Med 2001; 344: 1343-50.

[19] Torgerson JS, Hauptman J, Boldrin MN, et al. Xenical in the prevention of diabetes in obese subjects (XENDOS) study: a randomized study of orlistat as an adjunct to lifestyle changes for 
the prevention of type 2 diabetes in obese patients. Diabetes Care 2004; 27: 155-61.

[20] Christiansen T, Bruun JM, Madsen EL, et al. Weight loss maintenance in severely obese adults after an intensive lifestyle intervention: 2 - to 4-year follow-up. Obesity 2007, 15: 413-20.
[21] Svetkey LP, Stevens VJ, Brantley PJ, et al. Comparison of strategies for sustaining weight loss: The weight loss maintenance trial. JAMA 2008; 299: 1139-48.

[22] Martins C, Strømmen M, Stavne OA, et al. Surgery versus Lifestyle Intervention for Morbid Obesity - Changes in Body Weight, Risk Factors and Comorbidities at 1 year. Obes Surg. DOI 10 1007/s. 11695-010-0131-1.

Received: May 13, 2011

Revised: June 25, 2011

Accepted: June 28, 2011

(C) Skyrud et al.; Licensee Bentham Open.

This is an open access article licensed under the terms of the Creative Commons Attribution Non-Commercial License (http://creativecommons.org/licenses/by$\mathrm{nc} / 3.0 /$ ), which permits unrestricted, non-commercial use, distribution and reproduction in any medium, provided the work is properly cited. 